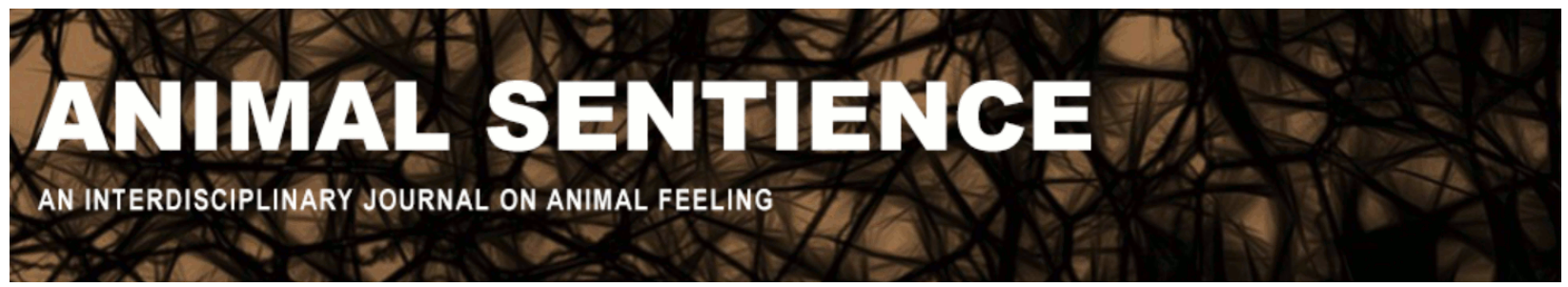

Preti, Antonio (2018) Animal suicide: Evolutionary continuity or anthropomorphism?. Animal Sentience 20(10)

DOI: $10.51291 / 2377-7478.1297$

Date of submission: 2018-01-14

Date of acceptance: 2018-01-16 (c) 


\title{
Animal suicide: Evolutionary continuity or anthropomorphism?
}

\author{
Commentary on Peña-Guzmán on Animal Suicide
}

\author{
Antonio Preti \\ University of Cagliari, Italy
}

\begin{abstract}
Evolutionary processes are characterized by both continuity and discontinuity. Evidence on suicide in nonhuman animals is faint and often rests on the metaphorical or anthropomorphic use of the term. Suicidal behavior might be an evolutionary jump relatively recent in our species: a byproduct of living in groups of people who are not as closely related genetically as in social groups of nonhuman mammals.
\end{abstract}

Keywords: suicide, animal consciousness, evolutionary continuity, genetics, sociobiology


The idea that animals can commit suicide is not new. It can be found in the writing of naturalists from the classical era, such as Aristotle (Historia Animalium, IX, 47), and in ancient collectors of oddities, such as Claudius Aelianus, writing in the $3^{\text {rd }}$ century of current era (Preti, 2005). Since ancient times, folk tales of suicide in animals have illustrated popular beliefs about suicide and reflected social values about beloved pets. Grief, desperation, and unbearably strong emotions were thought to be a drive toward suicide in nonhuman animals and humans. Ultimately, the alleged cases of suicide of dogs or horses were seen as a demonstration of feelings in animals, justifying their rights to be treated with care (Ramsden and Wilson, 2010).

In his target article, Peña-Guzmán (2017) introduces the issue of continuity between nonhuman animals and our species in relation to subjective self-awareness, and to free will and awareness of death in particular. Peña-Guzmán deserves credit for summarizing the depth and breadth of this issue. I agree with him that there is evolutionary continuity between nonhuman animals and homo sapiens in many functional brain phenomena that are related to suicide in humans. These phenomena are accessible to laboratory modeling, a helpful tool for investigating suicidal behavior (Gould et al., 2017). However, this does not demonstrate that nonhuman animals are actually capable of committing suicide.

Investigation across thousands of animal species has found no evidence of instances comparable to human suicide in field situations (de Catanzaro, 1980; Lester, 1992, 2000; Preti, 2007). In many scientific reports, the term "suicide" is applied metaphorically, as in the case of death during dispersal (the [in]famous case of lemmings), or in the "suicidal" attraction to predators of rodents parasitized by Toxoplasma gondii (further examples in Hamilton, 1980). The assimilation of altruistic behavior to suicide is also ungrounded, pace 
Durkheim, since people or animals that sacrifice their lives on behalf of their kin as a defensive behavior or in rescue operations usually do not aim to die (discussion in Preti, 2007). Most evidence comes from behavioral instances that, despite being related to suicidal behavior in humans, cannot be assimilated to it, such as self-endangering behavior or selfharm (Crawley et al., 1985). The deer that throws itself against the walls that keep it confined is not trying to kill itself but seeking a way to escape or attempting to destroy something that it perceives as evil and dangerous for its survival. Contrary to what PeñaGuzmán suggests, anecdotal evidence, such as the story of the dolphin ceasing to breath or the whales voluntarily looking for death by stranding themselves on the beach, is anthropomorphic fable only.

In my view, Peña-Guzmán is too fast in dismissing the role of "intention" in human suicide. I agree with him (and Lester, 2017) that in many instances suicidal persons would not have been able to make fully explicit the reasons for their self-killing act. However, I also think that suicide is the lethal outcome of actions that the deceased person had initiated knowing or expecting that fatal outcome, whatever the instrumental goal (see De Leo et al., 2006, for discussion). The intention to die is central in the definition of suicide in humans. The intention, in this context, can be identified with the purpose set during the completion of a given act; hence the death of someone falling to the ground from a window because they thought they could fly is not classified as a suicide with good reason.

I'm also reluctant to accept Peña-Guzmán's arguments based on "absolute continuity." There are evolutionary discontinuities in evolution; these define the boundaries between species. I'm ready to accept the challenge of considering suicidal behavior as one such discontinuity. According to de Catanzaro (1980, 1984, 1986), suicide relates to a diminished residual capacity to promote inclusive fitness, defined as the welfare and reproduction of the self and of kin. If - and this is a big "if" - suicidal behavior is under genetic control, then there can be a basis for an evolutionary continuity model of suicide across animal species.

Factors such as mental disorders, comorbidity with alcohol and substance-use disorders, accessibility to lethal means, and social isolation (which may involve less chance of social support, surveillance and prompt rescue) are all potentially important in human suicide and targets of preventative efforts (Preti, 2011). Yet most causes of suicide are connected to interpersonal relations: Separations and conflicts are the ones most commonly reported, particularly in impulsive attempts.

Since the development of agriculture, people have been increasingly living in groups that are not as closely related genetically as social groups of nonhuman mammals. Most social animals live in kin-groups. In humans, failure in a relational conflict, whether in pair bonding or social competition, may favor unrelated kin-lines. This rarely occurs in nonhuman animals. Suicidal behavior may have been co-selected with other genes involved in decisionmaking. Individuals who make bad decisions about genetically unrelated people pose a danger to their kin-line (e.g., dispersion of resources). A gene for suicide might have evolved recently as an alarm that potentiates a sense of guilt, shame, sadness, and fear.

Suicide seems to be rare in contemporary hunter-gatherer societies that might be similar to those of our Paleolithic ancestors (Hill et al., 2007; Moreno, 2011). Among these contemporary hunter-gatherer societies, descendants of the mitochondrial haplotype L3, but not those of $L 0, L 1$, and $L 2$, have a greater propensity to commit violence against others (homicide) and themselves (suicide) (Moreno, 2011). If suicide has a genetic basis, the descendants of the mitochondrial haplotype L3 might also carry the genes for suicide, which 
are separate from those for homicide, although there is a relationship between aggression towards others as well as oneself, perhaps mediated by impulsivity (Coccaro et al., 2015).

Suicide might also be a learned behavior (de Catanzaro, 1980; Lester, 1987). In that case, the debate about suicide in nonhuman animals would need to be reframed.

\section{References}

Coccaro, E.F., Fanning, J.R., Phan, K.L., \& Lee, R. (2015). Serotonin and impulsive aggression. CNS Spectrums, 20, 295-302.

Crawley, J.N., Sutton, M.E., \& Pickar, D. (1985). Animal models of self-destructive behavior and suicide. Psychiatric Clinics of North America, 8, 299-310.

de Catanzaro, D. (1980). Human suicide: a biological perspective. The Behavioral and Brain Sciences, 3, 265-290.

de Catanzaro, D. (1984). Suicidal ideation and the residual capacity to promote inclusive fitness: a survey. Suicide and Life-Threatening Behavior, 14(2), 75-87.

de Catanzaro, D. (1986). A mathematical model of evolutionary pressures regulating self-preservation and self-destruction. Suicide and Life-Threatening Behavior, 16(2), 166-181.

De Leo, D., Burgis, S., Bertolote, J.M., Kerkhof, A.J., \& Bille-Brahe, U. (2006). Definitions of suicidal behavior: lessons learned from the WHO/EURO multicentre Study. Crisis, 27(1), 4-15.

Gould, T.D., Georgiou, P., Brenner, L.A., Brundin, L., Can, A., Courtet, P., Donaldson, Z.R., Dwivedi, Y., Guillaume, S., Gottesman, I.I., Kanekar, S., Lowry, C.A., Renshaw, P.F., Rujescu, D., Smith, E.G., Turecki, G., Zanos, P., Zarate, C.A., Jr., Zunszain, P.A., \& Postolache, T.T. (2017). Animal models to improve our understanding and treatment of suicidal behavior. Translational Psychiatry, 7(4), e1092. doi: 10.1038/tp.2017.50.

Hamilton, W.J. (1980). Do nonhuman animals commit suicide? The Behavioral and Brain Sciences, 3, 278-279.

Hill, K., Hurtado, A.M., \& Walker, R.S. (2007). High adult mortality among Hiwi hunter-gatherers: implications for human evolution. Journal of Human Evolution, 52(4), 443-454.

Lester, D. (1987). Suicide as a learned behavior. Springfield, IL, England: Charles C. Thomas.

Lester, D. (1992). Suicidal behavior in lower animals. In Why people kill themselves: 1990s summary of research findings on suicidal behavior ( $3^{\text {rd }}$ ed.), Ed. Lester, D. Springfield, IL: Charles C. Thomas, 415-417.

Lester, D. (2000). Suicidal behavior in lower animals. In Why people kill themselves: 2000 summary of research findings on suicidal behavior ( $4^{\text {th }}$ ed.), Ed. Lester, D. Springfield, IL: Charles C. Thomas, 377-378.

Lester, D. (2017). Non-human animal suicide could be tested. Animal Sentience 20(3).

Moreno, E. (2011). The society of our "out of Africa" ancestors (I): the migrant warriors that colonized the world. Communicative \& Integrative Biology, 4(2), 163-170.

Peña-Guzmán, D.M. (2017). Can nonhuman animals commit suicide? Animal Sentience 20(1).

Preti, A. (2005). Suicide among animals: clues from folklore that may prevent suicidal behaviour in human beings. Psychological Reports, 97, 547-558.

Preti, A. (2007). Suicide among animals: a review of evidence. Psychological Reports, 101, 831-48.

Preti, A. (2011). Animal model and neurobiology of suicide. Progress in Neuro-Psychopharmacology \& Biological Psychiatry, 35(4), 818-830.

Ramsden, E., \& Wilson, D. (2010). The nature of suicide: science and the self-destructive animal. Endeavour, 34(1), 21-24. 